\title{
Entrepreneurial Errors in a Kaleidic Democracy
}

\author{
Simon Bilo*
}

Allegheny College

\begin{abstract}
Economic activity is a stream of interconnected experiments, where some are bound to fail. Such failures are costly and policy makers might aspire to mitigate them, particularly during economic crises. The mitigation can happen in two ways: through further entrepreneurial experimentation in the market process or through the political process. When the goal is to minimize uncertainty during economic crises, profit-seeking entrepreneurship should dominate political action. This is because while people easily understand that the goal motivating entrepreneurs is to stay in business and to keep revenues above costs, the goals driving bureaucrats and politicians are less predictable.
\end{abstract}

\section{JEL Codes: H11, H12}

Keywords: clusters of errors, democracy, kaleidics, misallocations, uncertainty

\section{Introduction}

Uncertainty, subjectivity, and purposeful behavior are three features of human interaction that constrain potential market outcomes but also politicians who want to regulate these outcomes. The features, however, play out differently in the market arena when compared to the political arena, and they lead to two separate response patterns to the same type of event, particularly to a cluster of entrepreneurial errors. Whereas political responses seem arbitrary to outside observers and inject into the economy additional uncertainty, the market gives people the incentives and the knowledge to respond to errors in a more constrained - and therefore more predictablepattern of creativity. As long as the overarching policy goal is to minimize economic uncertainty, using the term "uncertainty" here

\footnotetext{
* I thank Richard Wagner for valuable conversation that led to this paper, and Harry David and participants of the 2015 annual meeting of the Southern Economic Association for valuable comments and suggestions on the earlier drafts. I am responsible for all errors.
} 
not in the Knightian sense but to refer to the general unpredictability of the future, responses to clusters of entrepreneurial errors should be left out of the political arena of a democratic polity. This conclusion is in line with the theory of Big Players, which points out that entities and people, particularly those of the state, are less predictable when they are not subject to constraints of profit and loss (Butos and Koppl 1993, pp. 322-25; Koppl 2002). I add to this theory by explaining the lower predictability in the particular context of governmental response to a cluster of entrepreneurial errors.

Understanding the reasoning behind the conclusion that responses in the political arena to entrepreneurial errors relatively increase uncertainty starts with recognizing that uncertainty is a general characteristic of the world, which means that although the future might be imaginable, it is also unknowable (Lachmann 1976, p. 59). People living in an uncertain world therefore use their imaginations to envision the future, which inevitably leads to some errors later on. Such errors in entrepreneurial decisions represent allocations of production factors that entrepreneurs end up regretting, likely for being unprofitable or not profitable enough. Such an entrepreneur could, for example, be a car manufacturer who is not able to sell enough cars to cover at least his variable costs, or a real estate developer who overestimated the demand for apartments when she decided to build an apartment complex.

In addition to the option of letting entrepreneurs deal with entrepreneurial mistakes within the marketplace, people in democracies can hope to use the democratic political arena to respond to the mistakes in two analytically distinct ways. Their representatives can either decide on corrective actions in the parliamentary assembly or they can delegate the decisions to bureaucracy. Both types of responses face behavioral and epistemological constraints that lead to a less predictable pattern of allocations of production factors, which in comparison to the market-based solution increases the uncertainty in the economy. This conclusion combines Hayek's (1967) emphasis on the importance of pattern prediction and Sweezy's (1938) discussion of the role of the circumstances under which people form expectations. Hayek (1967) argues that while recognizing a pattern in a society does not allow us to perfectly predict the future, it does help us to rule out possible future states of the world that are inconsistent with the pattern. But one pattern can be more useful in ruling out potential future states than another, as Sweezy (1938, p. 236) recognizes, and it is in this 
sense that responses to previous entrepreneurial errors through the political arena introduce more uncertainty than entrepreneurial responses.

My discussion regarding the response to entrepreneurial errors through bureaucracies builds on Mises (1944), who argues that bureaucracies cannot be judged on the basis of profit-and-loss accounting because their output is not bought or sold through the marketplace. Since correcting entrepreneurial errors requires discretionary powers over the allocation of production factors, a bureaucrat given such a task makes decisions that have an arbitrary pattern from the perspective of outside observers. His resourceallocation decisions depend on his incentive structure, which is hard for observers to understand because it does not relate to a measurable, objective goal such as profit maximization.

Realizing the difficulties bureaucracies face to identify and fix errors, one might turn to a parliamentary assembly with the expectation that the assembly can give a proper hearing to the concerned parties and to the experts who understand the businesses at stake. With all the information, the assemblies can then decide which entrepreneurial errors to fix and how to do it, while being aware that they have to take responsibility for the decision in the next election. Unfortunately, even when parliamentarians have an incentive to search for genuine errors and to solve them, people who try to predict their actions still face the knowledge problem that results when parliamentarians supersede profit-and-loss calculation with other concerns. In addition, de Jouvenel (1961) points out that the assemblies also face a time constraint, which is more likely to become binding when several failing entrepreneurial projects compete for an assembly's attention during economic recessions. The time constraint then may skew the information the assembly receives, making its decision even less predictable. Both features of the parliamentary process thus make its results less predictable. To connect this observation with Koppl's (2002) argument, bureaucracies and the assemblies are Big Players, as their decisions tend to be "unrelated to anything objective, regular, and predictable" (p. 122). To predict them, one has to have what Machlup (1936) would consider to be a relatively intimate knowledge of specific decision-makers' preferences, which are often hard, if not impossible, to know.

The situation in the political arena contrasts in my framework with the free-market process, where profit-seeking entrepreneurs 
respond to the errors themselves. This is not because entrepreneurial decisions would be as good as the decisions of a fictitious ideal social planner. Rather, in contrast to parliaments and bureaucracies, one does not need intimate knowledge of particular people, in this case entrepreneurs, to be able to predict the pattern of their responses to previous entrepreneurial errors. While better predictability does not eliminate all the uncertainty in the economy, it comes with what one might call "constrained creativity" in the market process within which entrepreneurs are induced to respond to previous errors. Entrepreneurs seek profits, or at least try to avoid losses, which is a measurable goal under specific circumstances. This goal is permanently tested against visions of other entrepreneurs in the marketplace in a process Mises ([1920] 1990, p. 12) calls intellectual division of labor and Hayek calls ([1968] 2002) discovery procedure, where entrepreneurs continuously bid for production factors. In the sense that the constraints of profit seeking and intellectual division of labor are rules, constrained creativity is a rule-based response toward entrepreneurial errors. While it does not eliminate mistakes, which would be impossible, it makes the future more imaginable and predictable when compared to the situation where parliaments and bureaucracies respond to entrepreneurial errors, particularly when these errors come in large clusters like in recessions. As long as lower uncertainty is the main policy goal, my analysis leads to the policy recommendation to mitigate errors through the private-enterprise system. This recommendation is very much in line with Wagner's (2012) broader analysis that contrasts the private and public responses to macroeconomic shocks and recognizes that while we can measure these shocks through macroeconomic statistical aggregates, the responses can happen only on the microeconomic level. He concludes that private responses, which are based on voluntary relationships and residual claimancy, use dispersed information in their responses to the shocks better than public responses do.

The conclusion that bureaucracies and parliamentary assemblies inject relatively higher uncertainty into the economy when they decide to respond to a cluster of entrepreneurial errors adds a layer of explanation to related works on the topic. The injection of uncertainty that I explain can be understood as the source of the discoordinating negative shock to entrepreneurial alertness that Laer and Martin (2016, pp. 553-56) hypothesize in their conceptual framework that connects uncertainty and adverse economic 
performance. My discussion also relates to Pástor and Veronesi's (2013) model of government policy choice, in which adverse economic conditions induce government to offset them with a policy change. In the model, the prospect of change increases the political uncertainty in the economy because people have to estimate the content of the new policy. The change also means that people will have to learn about the new policy's impact, which increases the uncertainty regarding the policy change. While Pástor and Veronesi (2013) argue that new policies tend to increase uncertainty in general, I focus on the more specific scenario of the attempt to fix a cluster of entrepreneurial errors, about which I also provide a causal mechanism that connects new policy with an increase in uncertainty.

My framework finds empirical support in the recent literature on uncertainty that originates with Bloom (2009), who estimates uncertainty shocks and their macroeconomic impact. A stylized fact emerging from this literature is the countercyclical nature of uncertainty, as Bloom (2014) and Jurado, Ludvigson, and Ng (2015) point out. Moreover, this countercyclicality is, at least to some extent, explicable by underlying economic policy, as Higgs (1997) shows in his discussion of policy-induced regime uncertainty during the Great Depression. Baker, Bloom, and Davis (2013); Laer and Martin (2016); and Koppl (2014) show this for the Great Recession, and Pástor and Veronesi (2013) do so for the period January 1985-December 2010. This pattern of political uncertainty over the business cycle is consistent with my framework, where uncertainty arises during recessions because the public increases its demand for politicians and bureaucrats to fix the entrepreneurial errors that the higher prevalence of bankruptcies suggests (Altman 1983; Platt and Platt 1994; Santoro and Gaffeo 2009). The framework is also consistent with Baker et al. (2014), who find that government size positively correlates with economic-policy uncertainty, assuming that an increase in government size also means that government has to undertake more open-ended entrepreneurial functions.

\section{Uncertainty, Subjectivity, and Purposefulness of Human Action}

The underlying assumptions for my discussion of different institutional responses toward entrepreneurial errors pertain to three intertwined characteristics of human action: uncertainty, subjectivity, and purposefulness. People live in the world of uncertainty partly because the causal links between their present actions and the 
potential future consequences are blurred and people make mistakes. One cause of this type of uncertainty that is important for my discussion here relates to the subjective nature of how people evaluate choice alternatives. When a person decides today to accomplish some goal tomorrow, his success often depends on other people's choices, which are driven by their subjective preferences. These preferences by their nature cannot be directly experienced by the person, and he therefore can, and sometimes will, commit mistakes when trying to predict them.

Let's say the person is a monk living in a secluded place who decides he wants to eat a cake tomorrow. He can accomplish this goal only by walking overnight for twenty miles to the closest bus stop, taking a bus for another hundred miles to a town, and reaching the bakery that sells the cake he likes. Once he decides to do so, his success or failure depends, aside from the forces of nature, on other people's choices that are not given to him in advance. Perhaps the moody driver of the only bus that goes to the town will decide to not stop at the bus stop where the monk is waiting. Or perhaps the baker will decide to quit his job on the day of monk's arrival and the monk will arrive at a closed bakery. The monk's choice today to get a cake can turn out to be a mistake tomorrow because of other people's choices. As the choices are subjective, the monk cannot fully predict them. They inject uncertainty into the world and constrain those who-directly or indirectly_-depend on others' choices.

But choices are also constrained-even though they are subjective and inject genuine novelty into the world in the passage of time, as Shackle eloquently explains (1959, p. 293; see also Rizzo 2000). And the extent of the constraints and others' awareness of such constraints then injects more or less uncertainty into the world. It is perhaps this sort of constraint that is part of what Shackle (1959, p. 293; see also Rizzo 2000, p. 185) means by the term "bounded uncertainty." An obvious type of constraint is the endowment, which limits one's choices. But another type of constraint is important here: people also constrain themselves with their own purposes, as Kirzner ([1960] 1976, p. 162) points out. Since human action is purposeful, people act to get closer to fulfilling their own goals, making their actions more predictable to others. Like the police detective who narrows the group of suspects by understanding the potential motives behind a murder, one is able to narrow the set of potential future actions by understanding people's goals. For the same reasons, 
the more certain these goals are, the easier it is to predict the corresponding actions and to plan one's own actions.

In what follows, I show that identifying such goals when it comes to fixing a cluster of entrepreneurial errors is easier for people in the market process than in bureaucracies and parliamentary assemblies. In turn, the market-process responses to entrepreneurial errors are relatively more predictable and inject into the economy a pattern of lower, or more bounded, uncertainty.

\section{Responding to Entrepreneurial Errors through Bureaucracies}

What if a country experiences an unexpected economic recession? A number of people realize they have made mistakes in the number of workers they hired, investment projects they started, and debt they issued. These mistakes threaten specific human and physical capital incurred in the related projects and corresponding quasi-rents, as Bilo (2016) shows. Owners of these specific production factors - whether they are shareholders or workers-therefore have an incentive to demand that the government "do something." The government often decides to respond and save some of the negatively affected companies from shutting down.

While there are many ways for government to administer aidwhether through a subsidized loan, cash transfer, tax break, or some other means - the help requires scarce resources. The scarcity tends to become more binding during a recession, when the needs of failing companies that committed entrepreneurial errors tend to significantly exceed the available rescue funds and someone has to decide who gets the help and how to administer it. Such a decision is not routine but rather open-ended and creative; it is an entrepreneurial decision. When it is the task of a bureaucrat - that is, an unelected government employee-to select entrepreneurial errors to fix, he must perform creative entrepreneurial acts. For this reason, whatever the bureaucrat does, his performance cannot be judged on the basis of adherence to clearly defined rules and procedures, as it might be with many of his other tasks (Mises 1944). Such a reward system would be inappropriate because the bureaucrat's entrepreneurial creativity in this role cannot be prescribed and their results cannot be fully predicted; as Buchanan ([1969] 1999, p. 90) points out, a bureaucrat deciding in the world of uncertainty can only base his decisions on assigning subjective-probability coefficients to different future scenarios, and the correctness of these probability assignments can 
differ from person to person and cannot be objectively evaluated as right or wrong.

While the bureaucrat cannot be judged by his adherence to formal rules, he also cannot be subjected to the standard criterion of entrepreneurial decisions: profit-and-loss accounting. It is necessary to soften the budget constraint of a failing company, to use Kornai's (1986) terminology, and thereby to ignore the criterion of profit and loss for the time being because the company without such softening would go out of business; the bureaucrat would, in such a case, not be in charge of saving the company in the first place. Without clear rules and without the task of adhering to a hard budget constraint for particular companies, a recession, in which many failing companies need to be saved, gives discretionary powers to bureaucrats in charge of deciding which failing companies to save and how.

When using discretion over the fates of particular failing companies or their parts, each bureaucrat in charge becomes an entrepreneur bound neither by a budget constraint and economic calculation nor by clear rules. He is no residual claimant to his decisions, and he is not necessarily interested in the profitability of the company in question. Instead, he weights expected future performance with other goals that might be important to him and his superiors - such as the promised employment levels of the companies, their geographic location, the financial and nonfinancial ties of the companies to the ruling coalition, the bureaucrat's desired future political career, and many others. Unfortunately, these goals are often not publicly known. It might be hard to communicate all of them and their relative weights, and doing so might threaten the bureaucrat's career for their possible illegality or immorality. They also do not have a common denominator; external observers therefore cannot objectively rank their relative importance. Whichever company or part of a company the bureaucrat decides to save, the decision depends on his subjective preferences. It is therefore, in the eyes of other people, relatively arbitrary and unpredictable, and thereby injects additional uncertainty into the economic system. These injections continue as long as the bureaucrat is in charge.

\section{Responding to Entrepreneurial Errors through Democratic Parliaments}

Recognizing the entrepreneurial character of governmental responses to errors, one can suggest keeping the respective decisions with a 
parliamentary assembly rather than delegating them to bureaucracy, in the hope that democratic elections might provide desirable feedback for such decisions. But in deciding themselves rather than delegating, parliamentary assemblies also inject uncertainty into the economy in a similar way as bureaucracies do.

To recognize the source of this uncertainty, keep in mind that the nature of the problem the assemblies must solve is the same as that which I discussed with respect to bureaucrats. In the case of each failing company or part thereof about which the parliaments are making their decisions, the parliaments do so subject to a soft budget constraint. The criterion of profit and loss is necessarily superseded by other concerns-otherwise, the firm in question (or its part) would go out of business, and there would be no government intervention. Such other concerns, however, tend to have multiple dimensions that cannot be easily compared one to another, which makes the decision that parliaments have to make complex. The question of why to save company $A$ by means of tools $X$ might be very complicated when the alternative is to save company $B$ by means of tools $Y$.

The complexity of the parliamentary decision about saving a firm means that such decisions during economic crises, when the political demand for this type of action tends to increase, likely face the time constraint expressed by de Jouvenel (1961). The constraint arises in general from the limits on the parliamentary assembly's time to discuss a specific issue as well as from the attention the assembly members can pay to speakers. The time constraint tends to become more binding during economic recessions, when the assembly has to decide about potential rescue packages, as more firms or their parts tend to go out of business. The assembly and its committees may not have time or attention span to hear all the proposals and all the expert testimonies that pertain to such proposals. Assuming the potential proposals are sufficiently complex that it is hard to rank their relative importance before hearing them, it is hard for assembly members to judge whether to exclude a particular item from the agenda even though they have to do so. Allocating the time to different potential agenda items is then determined by the subjective judgment of particular individuals, or in terms of de Jouvenel's parable, the assembly chairman. The chairman uses his own discretion in considering the information the assembly receives when deciding whether and how it should respond to entrepreneurial errors. Exercising such discretion then raises uncertainty in a similar 
way to the discretion of a bureaucrat in the same situation. The chairman's concerns are not profit and loss and are likely multidimensional. And where he judges the different dimensions based on his subjective preferences, it is hard to predict which failing companies will even get on the agenda and which will be dismissed. Governmental involvement in failing companies during recessions through parliamentary assemblies injects additional uncertainty into the economy.

\section{Responding to Entrepreneurial Errors through the Market Process}

Public-policy responses to entrepreneurial errors are, however, not the only option, as I mentioned in the introduction. Rather than saving particular projects, the government can choose what people often consider the less desirable option: letting unprofitable projects fail. The response to errors is then that of the market process, where profit-seeking entrepreneurs bid for previously misallocated production factors to employ them in alternative uses. In contrast to governmental responses to errors, entrepreneurial responses have a pattern that can be understood without reference to the subjective preferences of particular entrepreneurs. This pattern bases itself on more-anonymous behaviors, as Machlup (1936) would describe it. It is this anonymity that makes the market process's results more predictable than the results of government interventions.

The predictability of the market-process pattern comes with an objective and quantifiable goal that entrepreneurs tend to strive for: the goal of keeping revenues above costs, which Alchian (1950) calls "pursuit of positive profits." Entrepreneurs strive for this goal because those who do not maintain positive profits tend to be eliminated from the marketplace. Such a goal is likely only intermediate for a particular entrepreneur, as he might want to keep his company afloat for various reasons. Perhaps he wants to maximize profits, or he enjoys having a business, or he likes his employees and would feel bad about firing them. But whatever the underlying reason why entrepreneurs desire to stay in business, it is not really important to other market participants. This irrelevance of the underlying causes is analogous to the role of the price system in transmitting dispersed knowledge, as Hayek (1945) discusses. It often does not matter to market participants why certain price movements happen: the very existence of the movements conveys all the information they need to know. In a similar way, the fact that market 
participants and other outside observers understand an entrepreneur's intermediate goal is enough for them to rule out some of his possible future actions within a given historical context and to predict the future better.

The predictable pattern of the market process tends to hold for all market participants because all are subject to the same rules of profit and loss. This means that even in a recession, with numerous failed entrepreneurial projects and struggling companies, which my paper focuses on, all owners of the production factors involved in these projects follow the same pattern: unprofitable enterprises tend to discontinue, which makes the production factors they employed available to more profitable employments. The price system, in the mentioned fashion of Hayek (1945), then informs participants what these employments could be. Of course, current prices are not necessarily identical to the future prices; however, future prices do not emerge without a connection to the prices of the immediate past, as Mises (1998, p. 334) and Rizzo (2000, p. 180) point out. To the extent that our present and future actions and preferences are interconnected, the prices of the immediate past convey some information about what future employments of factors in the presently failing industries could be.

The pattern of the entrepreneurial market response to a cluster of previous entrepreneurial errors then differs from the two types of government responses I discussed in the previous sections. It tends to inject the economy with relatively less uncertainty. When members of parliament or bureaucrats respond to entrepreneurial errors, the outside observer does not have insight into the goals driving the bureaucrats' or politicians' decisions. Without such insights, their actions appear arbitrary to the observer: the environment of a soft budget constraint does not force upon them the intermediate goal of pursuing positive profits in the way that the market process does on entrepreneurs. As a result, there is no equivalent to the signals of profit and loss that would give the observer clues to narrow the possible future options that bureaucrats and politicians perceive for responding to particular failing businesses. This higher openendedness of potential governmental responses to a cluster of entrepreneurial errors in comparison to the responses in the market process then means that the market process introduces relatively less uncertainty. 


\section{Conclusion}

While the future is imaginable, it is also unknowable (Lachmann 1976). Economic activity is then a stream of interconnected experiments, some of which are bound to fail. The failures are costly because they involve irreversible investments and they affect the viability of other experiments. This costliness often makes failures politically undesirable, and although one cannot hope to fully eliminate them, people can suggest mitigating the consequences of previous entrepreneurial failures as a desirable policy goal, especially when the failures come in a cluster. Such mitigation can happen in two fundamental ways in a democratic polity: through additional entrepreneurial experimentation in the market process or through discretion in the political process. When the goal is to minimize people's uncertainty in the face of such a cluster of entrepreneurial errors, as during recessions, the entrepreneurial response dominates political discretion. Politicians and bureaucrats' decision criteria are by their nature less comprehensible and communicable when compared to the intermediate entrepreneurial goal of staying in business.

The policy recommendation for mitigating failures is identical to the recommendation implied by Kydland and Prescott's (1982) real business cycle theory, albeit with a different underlying argument. In real business cycle theory, political discretion only appears inappropriate by assuming perfect competition and general equilibrium. In contrast, I argue that while disequilibrium is an inevitable feature of the world, entrepreneurial experimentation can systematically mitigate the consequences of failures and inject less uncertainty into the economy than the alternatives from the political arena can. This argument is very much in line with the empirical evidence from the introduction that shows that the current countercyclical pattern of uncertainty is at least partly caused by economic policies.

\section{References}

Alchian, Armen A. 1950. "Uncertainty, Evolution, and Economic Theory." Journal of Political Economy, 58(3): 211-21.

Altman, Edward I. 1983. "Why Businesses Fail." Journal of Business Strategy, 3(4): 1521.

Baker, Scott R., Nicholas Bloom, Brandice Canes-Wrone, Steven J. Davis, and Jonathan Rodden. 2014. "Why Has US Policy Uncertainty Risen since 1960?" American Economic Review, 104(5): 56-60. 
Baker, Scott R., Nicholas Bloom, and Steven J. Davis. 2013. "Measuring Economic Policy Uncertainty.” Chicago Booth Research Paper 13-02.

Bilo, Simon. 2016. "Who Seeks Quasi-Rents at the Shutdown Point?" Social Science Research Network Working Paper 2808797.

Bloom, Nicholas. 2009. The Impact of Uncertainty Shocks. Econometrica, 77(3): 623-85.

Bloom, Nicholas. 2014. "Fluctuations in Uncertainty." Journal of Economic Perspectives, 28(2): 153-76.

Buchanan, James M. (1969) 1999. Cost and Choice: An Inquiry in Economic Theory. The Collected Works of James M. Buchanan, vol. 6. Indianapolis, IN: Liberty Fund.

Butos, William N., and Roger G. Koppl. 1993. "Hayekian Expectations: Theory and Empirical Applications." Constitutional Political Economy, 4(3): 303-29.

De Jouvenel, Bertrand. 1961. "Seminar Exercise: The Chairman's Problem." American Political Science Review, 55(2): 368-72.

Hayek, Friedrich August von. 1945. "The Use of Knowledge in Society." American Economic Review, 35(4): 519-30.

Hayek, Friedrich August von. 1967. "The Theory of Complex Phenomena: A Precocious Play on the Epistemology of Complexity." In Studies in Philosophy, Politics and Economics, ed. Friedrich August von Hayek, 22-42. Chicago: University of Chicago Press.

Hayek, Friedrich August von. (1968) 2002. "Competition as a Discovery Procedure." Quarterly Journal of Austrian Economics, 5(3): 9-23.

Higgs, Robert. 1997. "Regime Uncertainty: Why the Great Depression Lasted So Long and Why Prosperity Resumed after the War." Independent Review, 1(4): 561-90.

Jurado, Kyle, Sydney C. Ludvigson, and Serena Ng. 2015. "Measuring Uncertainty." American Economic Review, 105(3): 1177-1216.

Kirzner, Israel M. (1960) 1976. The Economic Point of View: An Essay in the History of Economic Thought. 2nd ed. Kansas City, MO: Sheed and Ward.

Koppl, Roger. 2002. Big Players and the Economic Theory of Expectations. New York: Palgrave Macmillan.

Koppl, Roger. 2014. From Crisis to Confidence: Macroeconomics after the Crash. Vol. 175. London: Institute of Economic Affairs.

Kornai, Janos. 1986. "The Soft Budget Constraint.” Kyklos, 39(1): 3-30.

Kydland, Finn E., and Edward C. Prescott. 1982. "Time to Build and Aggregate Fluctuations." Econometrica, 50(6): 1345-70.

Lachmann, Ludwig M. 1976. "From Mises to Shackle: An Essay on Austrian Economics and the Kaleidic Society." Journal of Economic Literature, 14(1): 5462.

Laer, Wolf von, and Adam Martin. 2016. "Regime Uncertainty and the Great Recession: A Market-Process Approach.” Independent Review, 20(4): 547-68.

Machlup, Fritz. 1936. “Why Bother with Methodology?” Economica, 3(9): 39-45.

Mises, Ludwig von. (1920) 1990. Economic Calculation in the Socialist Commonwealth. Auburn, AL: Ludwig von Mises Institute.

Mises, Ludwig von. 1944. Bureaucracy. New Haven, CT: Yale University Press.

Mises, Ludwig von. 1998. Human Action: A Treatise on Economics. The Scholar's Edition. Auburn, AL: Ludwig von Mises Institute. 
Pástor, Luboš, and Pietro Veronesi. 2013. "Political Uncertainty and Risk Premia." Journal of Financial Economics, 110(3): 520-45.

Platt, Harlan D., and Marjorie B. Platt. 1994. "Business Cycle Effects on State Corporate Failure Rates." Journal of Economics and Business, 46(2): 113-27.

Rizzo, Mario J. 2000. "Real Time and Relative Indeterminacy in Economic Theory." In Time in Contemporary Intellectual Thought, Vol. 2, ed. Patrick Baert, 171-88. Amsterdam, The Netherlands: Elsevier Science B.V.

Santoro, Emiliano, and Edoardo Gaffeo. 2009. "Business Failures, Macroeconomic Risk and the Effect of Recessions on Long-Run Growth: A Panel Cointegration Approach." Journal of Economics and Business, 61(6): 435-52.

Shackle, George L.S. 1959. "Time and Thought." British Journal for the Philosophy of Science, 9(36): 285-98.

Sweezy, Paul M. 1938. "Expectations and the Scope of Economics." Review of Economic Studies, 5(3): 234-37.

Wagner, Richard E. 2012. "Viennese Kaleidics: Why It's Liberty More Than Policy That Calms Turbulence." Review of Austrian Economics, 25(4): 283-97. 